\title{
MODEL OPTIMASI PENENTUAN KOMBINASI PRODUK MENGGUNAKAN METODE LINEAR PROGRAMMING PADA PERUSAHAAN BIDANG FASHION
}

\author{
Marcella Marsetiani \\ PT Astakarya Busanaprima \\ Jln. Sawo Kav 25, Jakarta Selatan, DKI Jakarta \\ marcella.marsetiani@yahoo.com
}

\begin{abstract}
The aims of this research are to determine the most optimal method for sales forecasting, to show the number of sales forecast on March 2014, and to determine the appropriate and efficient product mix should be produced by PT Astakarya Busanaprima within the fashion industry. This research used six forecasting methods and linear programming technique by maximize function with eight decision variables: jackets, dresses, blouses, kebaya, caftans, skirts, pants, and shawls also with constrained factors: available time for work, primarily material, supporting material, and demand fluctuation. The results show that the best forecasting method for the company was linear regression which predicted that 17 jackets, 247 dresses, 78 blouses, 42 kebaya, 12 caftans, 15 skirts, 17 pants, and 4 shawls would be sold on March 2014. The appropriate and efficient product mix that should be produced on March 2014 are 17 jackets, 70 dresses, 78 blouses, 42 kebaya, 12 caftans, 15 skirts, 17 pants, and 4 shawls.
\end{abstract}

Keywords: optimization, forecasting, linear programming, maximization, product mix

\begin{abstract}
ABSTRAK
Penelitian ini bertujuan untuk mengetahui metode peramalan apakah yang paling optimal, berapa banyak peramalan jumlah penjualan yang dapat diperoleh, dan kombinasi produk yang tepat dan efisien yang harus diproduksi oleh PT Astakarya Busanaprima yang bergerak di bidang fashion dan memproduksi pakaian jadi khusus wanita. Dalam melakukan peramalan jumlah penjualan, digunakan enam metode teknik peramalan, sedangkan penentuan kombinasi produk yang harus diproduksi dianalisis dengan teknik program linier dimana formulasi model dengan fungsi tujuan maksimisasi, delapan variabel keputusan (jacket, dress, blouse, kebaya, kaftan, skirt, pants, dan shawl), dan empat batasan model yang utama (jumlah jam kerja yang tersedia, bahan baku utama, bahan pendukung, dan fluktuasi permintaan). Hasil menunjukkan bahwa metode peramalan yang paling baik bagi perusahaan adalah regresi linier, yang pada periode Maret 2014 diramalkan bahwa 17 unit jacket, 247 unit dress, 78 unit blouse, 42 unit kebaya, 12 unit kaftan, 15 unit skirt, 17 unit pants, dan 4 unit shawl akan terjual. Kombinasi produk yang tepat dan efisien yang harus diproduksi pada periode Maret 2014 adalah 17 unit jacket, 70 unit dress, 78 unit blouse, 42 unit kebaya, 12 unit kaftan, 15 unit skirt, 17 unit pants, dan 4 unit shawl.
\end{abstract}

Kata kunci: optimasi, peramalan, pemrograman linier, maksimasi, kombinasi produk 


\section{PENDAHULUAN}

PT Astakarya Busanaprima merupakan perusahaan yang bergerak dalam industri fashion dan memproduksi pakaian jadi khusus wanita. Masalah utama yang terjadi pada PT Astakarya Busanaprima adalah fluktuasi tingkat permintaan pada jumlah penjualan (Gambar 1). Sedangkan input (sumber daya) memiliki keterbatasan, sehingga diperlukan pengalokasian resources yang tepat dan tata kelola sistem manajemen yang baik. Dengan pengalokasian dan tata kelola yang baik, PT Astakarya Busanaprima dapat memenuhi setiap permintaan yang ada. Maka dari itu, penentuan target produksi yang tepat diperlukan agar jumlah yang diproduksi dapat menjawab permintaan pasar tepat sasaran di tengah banyaknya produk atau pesaing yang beredar di pasar mode. Dengan demikian, tidak terjadi over-production ataupun over-capacity. Jika jumlah produksi melebihi jumlah permintaan, dapat menyebabkan pengembalian barang (retur) dari store yang terpaksa harus disimpan di gudang. Penumpukan barang dalam jangka waktu yang lama akan memakan banyak biaya.

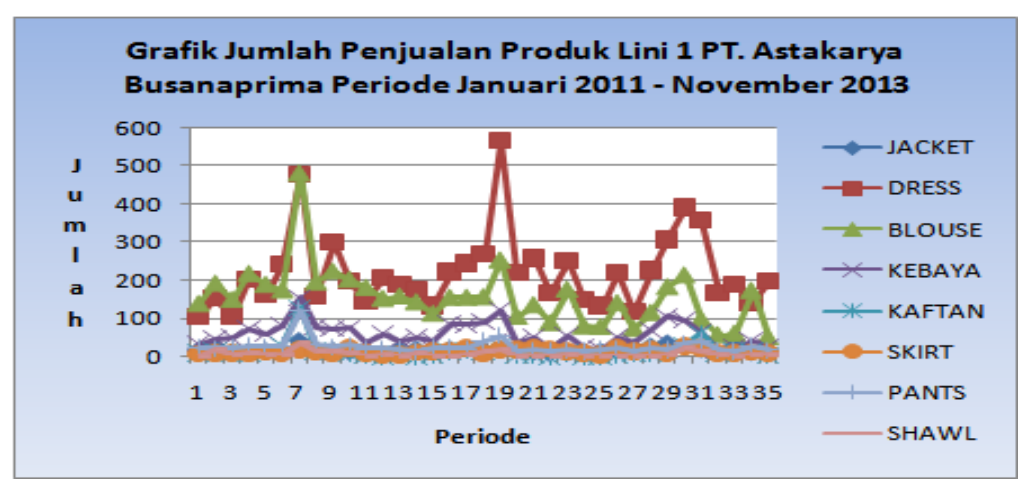

Gambar 1 Grafik Jumlah Penjualan (2011-2013)

(Sumber: PT Astakarya Busanaprima)

Berdasarkan latar belakang yang telah dikemukakan, formulasi masalah dalam penelitian ini adalah pertama, metode peramalan apakah yang paling optimal bagi PT Astakarya Busanaprima. Kedua, berapa banyak peramalan jumlah penjualan yang dapat diperoleh PT Astakarya Busanaprima pada periode Maret 2014. Ketiga, bagaimana kombinasi produk yang tepat dan efisien yang harus diproduksi oleh PT Astakarya Busanaprima pada periode Maret 2014. Untuk itu, penelitian ini bertujuan untuk, pertama, mengetahui metode peramalan apakah yang paling optimal bagi PT Astakarya Busanaprima. Kedua, untuk mengetahui berapa banyak peramalan jumlah penjualan yang dapat diperoleh PT Astakarya Busanaprima pada periode Maret 2014. Ketiga, untuk mengetahui kombinasi produk yang tepat dan efisien yang harus diproduksi oleh PT Astakarya Busanaprima pada periode Maret 2014.

\section{Landasan Teori}

\section{Optimasi Produksi}

Optimasi produksi adalah suatu cara untuk merencanakan atau mengatur penggunaan sumber daya yang dimiliki perusahaan, seperti: bahan baku, tenaga kerja, modal kerja, dan fasilitas produksi supaya dapat memenuhi permintaan konsumen, mengoptimalkan bahan baku yang ada dan agar proses produksi dapat berjalan dengan efektif dan efisien. Beberapa cara untuk dapat mengoptimalkan produksi, yakni: meningkatkan kualitas produksi, manfaat produksi, bentuk fisik produksi, dan mengatur jumlah produksi (Astuti, Linawati, \& Mahatma, 2013). Adapun beberapa teknik penyelesaian dalam menentukan optimasi produksi. Salah satunya adalah model program matematis, 
yang termasuk pada klasifikasi umum untuk model alokasi dalam menentukan keputusan optimal dan pola dari alokasi sumber daya (Igwe \& Onyenweaku, 2013).

\section{Forecasting}

Peramalan (forecasting) adalah suatu upaya untuk memperoleh gambaran mengenai apa yang akan terjadi di masa mendatang, yang akan menjadi dasar dalam membuat perencanaan. Nilai strategis dari fungsi peramalan dan perencanaan dapat dinyatakan sebagai "bridging the gap between where we are now and where we want to be" (Wignjosoebroto, 2003:337). Menurut Gass dan Fu (2013), peramalan diperlukan jika terdapat ketidakpastian dan banyak pula situasi yang penuh dengan ketidakpastian, sehingga prosedur peramalan yang tepat dapat membantu dalam mengurangi dan menilai ketidakpastian juga membantu para manajer untuk dapat mengambil keputusan dengan lebih baik lagi.

\section{Linear Programming}

Banyak keputusan utama yang dihadapi oleh seorang manajer perusahaan untuk mencapai tujuan perusahaan dengan batasan situasi lingkungan operasi. Pembatasan tersebut meliputi sumber daya, misalnya : waktu, tenaga kerja, energi, bahan baku, atau uang; atau dapat berupa bentuk batasan pedoman, misalnya resep untuk membuat makanan atau spesifikasi teknik. Secara umum, tujuan perusahaan yang paling sering terjadi adalah sedapat mungkin memaksimalkan laba atau meminimalkan biaya. Saat manajer berusaha untuk menyelesaikan masalah dengan mencari tujuan yang dibatasi oleh batasan tertentu, metode program linier sering digunakan (Taylor, 2005). Adapun metode ini menurut Render, Stair, dan Hanna (2012:270): "Linear programming is a technique that helps in resource allocation decisions." Hal ini berarti bahwa program linier adalah teknik yang membantu dalam keputusan-keputusan pengalokasian sumber daya. Salah satu permasalahan yang paling sering terjadi dalam program linier adalah permasalahan kombinasi produk dimana program linier digunakan untuk memutuskan berapa banyak yang harus diproduksi untuk masing-masing produk di tengah keterbatasan-keterbatasan sumber daya yang dimiliki.

\section{METODE}

Untuk mengetahui hasil peramalan permintaan digunakan software QM for Windows 2. Metode perhitungan peramalan yang digunakan terdiri dari naive method, moving average, weighted moving average, exponential smoothing, exponential smoothing with trend, dan linear regression. Sekalipun belum ada metode yang dapat meramalkan secara akurat, tujuan digunakan beberapa metode tersebut untuk memperoleh perbandingan ukuran akurasi hasil peramalan yang dapat dilihat dari Mean Absolute Deviation (MAD), yang menurut Heizer dan Render (2009) "merupakan ukuran pertama kesalahan peramalan keseluruhan untuk sebuah model". Penelitian ini menggunakan data historis jumlah penjualan periode Januari 2011 hingga November 2013 dari masing-masing produk untuk melakukan forecasting pada periode Maret 2014.

Berikut ini adalah formulasi model yang digunakan dalam metode Linear Programming:

Variabel Keputusan:
a. Jumlah Jacket $=\mathrm{x}_{1}$
b. Jumlah Dress $=\mathrm{x}_{2}$
c. Jumlah Blouse $=x_{3}$
d. Jumlah Kebaya $=x_{4}$
e. Jumlah Kaftan $=x_{5}$
f. Jumlah Skirt $=\mathrm{x}_{6}$
g. Jumlah Pants $=\mathrm{x}_{7}$
h. Jumlah Shawl $=\mathrm{x}_{8}$ 
Fungsi Tujuan:

Maksimisasi $\mathrm{Z}=4.000 .000 \mathrm{x}_{1}+4.400 .000 \mathrm{x}_{2}+3.250 .000 \mathrm{x}_{3}+3.300 .000 \mathrm{x}_{4}+3.600 .000 \mathrm{x}_{5}+$ $1.575 .000 \mathrm{x}_{6}+1.575 .000 \mathrm{x}_{7}+3.500 .000 \mathrm{x}_{8}$

Fungsi Kendala:
a. Waktu
$: 14 \mathrm{x}_{1}+23 \mathrm{x}_{2}+21,5 \mathrm{x}_{3}+14 \mathrm{x}_{4}+21,5 \mathrm{x}_{5}+8 \mathrm{x}_{6}+8 \mathrm{x}_{7}+16 \mathrm{x}_{8} \leq 24.960$
b. Kain Jenis I
$: 5 \mathrm{x}_{2}+3 \mathrm{x}_{3}+2,5 \mathrm{x}_{4}+3 \mathrm{x}_{5}+2,75 \mathrm{x}_{6}+1,5 \mathrm{x}_{7}+2,25 \mathrm{x}_{8} \leq 2.500$
c. Kain Jenis II
$: 1,75 \mathrm{x}_{1} \leq 250$
d. Benang
$: 3 x_{1}+3 x_{2}+3 x_{3}+3 x_{4}+3 x_{5}+3 x_{6}+3 x_{7}+3 x_{8} \leq 1.200$
e. Benang bordir : $2 \mathrm{x}_{1}+3 \mathrm{x}_{2}+\mathrm{x}_{3}+\mathrm{x}_{4}+\mathrm{x}_{5}+0,5 \mathrm{x}_{6}+0,5 \mathrm{x}_{7}+\mathrm{x}_{8} \leq 400$
f. Lapisan dalam : $1,5 \mathrm{x}_{1}+2,5 \mathrm{x}_{2}+2,5 \mathrm{x}_{3}+2,5 \mathrm{x}_{5}+\mathrm{x}_{6}+1,5 \mathrm{x}_{7} \leq 575$
g. Kain keras
$: 2,5 \mathrm{x}_{1}+\mathrm{x}_{6}+\mathrm{x}_{7} \leq 150$
h. Manik-manik
$: 90 \mathrm{x}_{1}+90 \mathrm{x}_{2}+90 \mathrm{x}_{3}+100 \mathrm{x}_{4}+100 \mathrm{x}_{5}+40 \mathrm{x}_{6}+40 \mathrm{x}_{7}+120 \mathrm{x}_{8} \leq 35.000$
i. Retsleting
$: \mathrm{x}_{2}+\mathrm{x}_{6}+\mathrm{x}_{7}+\mathrm{x}_{8} \leq 150$
j. Kancing
$: 7 x_{1}+27 x_{2}+7 x_{3}+7 x_{4}+9 x_{5}+x_{6}+x_{7} \leq 3.000$
k. Jacket
$: \mathrm{x}_{1} \leq 17$
1. Dress
$: \mathrm{x}_{2} \leq 247$
m. Blouse
$: \mathrm{x}_{3} \leq 78$
n. Kebaya
$: \mathrm{x}_{4} \leq 42$
o. Kaftan
$: \mathrm{x}_{5} \leq 12$
p. Skirt
$: \mathrm{x}_{6} \leq 15$
q. Pants
$: \mathrm{x}_{7} \leq 17$
r. Shawl
$: \mathrm{x}_{8} \leq 4$

\section{HASIL DAN PEMBAHASAN}

Tabel 1 - Tabel 8 menunjukkan perbandingan peramalan produk di PT Astakarya Busanaprima menggunakan naive method, moving average, weighted moving average, exponential smoothing, exponential smoothing with trend, dan linear regression.

Tabel 1 Tabel Perbandingan Hasil Peramalan Jacket

\begin{tabular}{lccl}
\hline \multicolumn{1}{c}{ METODE } & FORECAST & MAD & \multicolumn{1}{c}{ MSE } \\
\hline Naive Method & 15 & 7,1176 & 106,1765 \\
Moving Average (dengan $\mathrm{n}=3)$ & 16,6667 & 7,1563 & 86,1146 \\
Weighted Moving Average $(0,5 ; 0,3 ; 0,2)$ & 15,3 & 7,0031 & 83,2828 \\
Exponential Smoothing $(\alpha=0,2)$ & 16,7136 & 6,929 & 74,5397 \\
Exponential Smoothing with Trend $(\alpha=0,3$ dan $\beta=0,4)$ & 14,8251 & 8,2155 & 106,4824 \\
Linear Regression $(\mathbf{y}=\mathbf{1 3 , 8 6 5 5 5}+\mathbf{0 , 0 7 7 3 x )}$ & 16,6487 & $\mathbf{6 , 0 6 8 6}$ & 64,9528 \\
\hline
\end{tabular}

Sumber: Peneliti (2013)

Tabel 2 Tabel Perbandingan Hasil Peramalan Dress

\begin{tabular}{lccl}
\hline \multicolumn{1}{c}{ METODE } & FORECAST & MAD & \multicolumn{1}{c}{ MSE } \\
\hline Naive Method & 197 & 94,8529 & $16.303,85$ \\
Moving Average $($ dengan $\mathrm{n}=3)$ & 175,6667 & 90,6146 & $13.610,84$ \\
Weighted Moving Average $(0,5 ; 0,3 ; 0,2)$ & 178,7 & 88,8563 & $13.189,06$ \\
Exponential Smoothing $(\alpha=0,2)$ & 216,2291 & 79,0205 & $11.947,96$ \\
Exponential Smoothing with Trend $(\alpha=0,3$ dan $\beta=0,4)$ & 199,6136 & 105,5443 & 17.030 \\
Linear Regression $(\mathbf{y}=\mathbf{1 9 8 , 9 9 5}+\mathbf{1 , 2 2 8 9 x})$ & 243,2336 & $\mathbf{7 0 , 0 1 9 4}$ & $9.824,359$ \\
\hline
\end{tabular}

Sumber: Peneliti (2013) 
Tabel 3 Tabel Perbandingan Hasil Peramalan Blouse

\begin{tabular}{llcc}
\hline \multicolumn{1}{c}{ METODE } & FORECAST & MAD & MSE \\
\hline Naive Method & 50 & 64,4706 & $9.055,823$ \\
Moving Average $($ dengan $\mathrm{n}=3)$ & 94,3333 & 59,4896 & $6.169,982$ \\
Weighted Moving Average $(0,2 ; 0,3 ; 0,5)$ & 88,9 & 59,7906 & $6.432,901$ \\
Exponential Smoothing $(\alpha=0,2)$ & 107,0753 & 53,1137 & $5.611,461$ \\
Exponential Smoothing with Trend $(\alpha=0,3$ dan $\beta=0,4)$ & 87,1676 & 67,3178 & $7.008,067$ \\
Linear Regression $(\mathbf{y}=\mathbf{2 2 2 , 8 8 2 4}-\mathbf{3 , 7 3 x )}$ & 88,6034 & $\mathbf{4 3 , 1 3 2 3}$ & $4.373,496$ \\
\hline
\end{tabular}

Sumber: Peneliti (2013)

Tabel 4 Tabel Perbandingan Hasil Peramalan Kebaya

\begin{tabular}{lccc}
\hline \multicolumn{1}{c}{ METODE } & FORECAST & MAD & MSE \\
\hline Naive Method & 21 & 25,1765 & $1.071,588$ \\
Moving Average (dengan $\mathrm{n}=3)$ & 28,3333 & 27,4167 & $1.138,722$ \\
Weighted Moving Average $(0,5 ; 0,3 ; 0,2)$ & 27,3 & 25,8375 & $1.038,253$ \\
Exponential Smoothing $(\alpha=0,2)$ & 42,0678 & 25,7616 & $1.076,713$ \\
Exponential Smoothing with Trend $(\alpha=0,3$ dan $\beta=0,4)$ & 27,0736 & 33,0039 & $1.546,76$ \\
Linear Regression $(\mathbf{y}=\mathbf{7 2 , 2 5 2 1}-\mathbf{0 , 7 8 5 4 x )}$ & 43,9765 & $\mathbf{2 3 , 4 6 8 1} 878,7197$ \\
\hline
\end{tabular}

Sumber: Peneliti (2013)

Tabel 5 Tabel Perbandingan Hasil Peramalan Kaftan

\begin{tabular}{lccc}
\hline \multicolumn{1}{c}{ METODE } & FORECAST & MAD & MSE \\
\hline Naive Method & 4 & 14,0588 & 810,7059 \\
Moving Average (dengan $\mathrm{n}=3)$ & 12,6667 & 16,1458 & 701,2016 \\
Weighted Moving Average $(0,5 ; 0,3 ; 0,2)$ & 10,5 & 15,5313 & 682,0031 \\
Exponential Smoothing $(\alpha=0,2)$ & 16,1161 & 13,7891 & 568,9147 \\
Exponential Smoothing with Trend $(\alpha=0,3$ dan $\beta=0,4)$ & 19,2285 & 19,2461 & 787,4888 \\
Linear Regression $(\mathbf{y}=\mathbf{1 8 , 4 9 5 8}-\mathbf{0 , 1 7 6 8 x})$ & 12,1328 & $\mathbf{1 2 , 0 5 4 2}$ & 489,2574 \\
\hline
\end{tabular}

Sumber: Peneliti (2013)

Tabel 6 Tabel Perbandingan Hasil Peramalan Skirt

\begin{tabular}{lccc}
\hline \multicolumn{1}{c}{ METODE } & FORECAST & MAD & MSE \\
\hline Naive Method & 7 & 5,7941 & 57,8529 \\
Moving Average (dengan n=3) & 8 & 5,6771 & 47,4271 \\
Weighted Moving Average $(0,5 ; 0,3 ; 0,2)$ & 7,9 & 5,5719 & 46,6066 \\
Exponential Smoothing $(\alpha=0,2)$ & 11,5209 & 5,1747 & 37,3677 \\
Exponential Smoothing with Trend $(\alpha=0,3$ dan $\beta=0,4)$ & 7,9761 & 5,6486 & 47,6082 \\
Linear Regression $(\mathbf{y}=\mathbf{9 , 7 3 9 4 9 5}+\mathbf{0 , 1 3 1 9 x})$ & 14,4891 & $\mathbf{4 , 6 4 2 9}$ & 31,4687 \\
\hline
\end{tabular}

Sumber: Peneliti (2013)

Tabel 7 Tabel Perbandingan Hasil Peramalan Pants

\begin{tabular}{lccc}
\hline \multicolumn{1}{c}{ METODE } & FORECAST & MAD & MSE \\
\hline Naive Method & 16 & 12,5 & 622,147 \\
Moving Average (dengan $\mathrm{n}=3)$ & 18,3333 & 13,3438 & 489,6562 \\
Weighted Moving Average $(0,5 ; 0,3 ; 0,2)$ & 18,4 & 13,1969 & 493,569 \\
Exponential Smoothing $(\alpha=0,2)$ & 21,0851 & 11,6096 & 401,4722 \\
Exponential Smoothing with Trend $(\alpha=0,3$ dan $\beta=0,4)$ & 21,9515 & 15,6916 & 556,923 \\
Linear Regression $(\mathbf{y}=\mathbf{3 2 , 9 2 4 3 7}-\mathbf{0 , 4 2 4 4 x )}$ & 17,6471 & $\mathbf{1 0 , 4 6 8}$ & 333,435 \\
\hline
\end{tabular}

Sumber: Peneliti (2013) 
Tabel 8 Tabel Perbandingan Hasil Peramalan Shawl

\begin{tabular}{lccc}
\hline \multicolumn{1}{c}{ METODE } & FORECAST & MAD & MSE \\
\hline Naive Method & 3 & 5,9412 & 79,5294 \\
Moving Average $($ dengan $\mathrm{n}=3)$ & 3 & 5,9583 & 70,8333 \\
Weighted Moving Average $(0,5 ; 0,3 ; 0,2)$ & 3,1 & 5,5875 & 65,6519 \\
Exponential Smoothing $(\alpha=0,2)$ & 5,057 & 5,3432 & 63,1013 \\
Exponential Smoothing with Trend $(\alpha=0,3$ dan $\beta=0,4)$ & 5,4667 & 7,1395 & 86,3518 \\
Linear Regression $(\mathbf{y}=\mathbf{9 , 0 4 3 6 9 7}-\mathbf{0 , 1 5 3 2 x})$ & 3,5277 & $\mathbf{4 , 9 8 9 5}$ & 50,2095 \\
\hline
\end{tabular}

Sumber: Peneliti (2013)

Berdasarkan hasil peramalan, diketahui bahwa metode Linear Regression merupakan yang terbaik dikarenakan memiliki angka MAD yang terkecil. Dengan demikian, persamaan regresi dapat digunakan untuk meramalkan jumlah penjualan tiap produk pada periode Maret 2014, sebagai berikut.

Tabel 9 Hasil Peramalan Jumlah Penjualan Periode Maret 2014

\begin{tabular}{|c|c|c|c|c|c|}
\hline PRODUK & & \multicolumn{2}{|c|}{ PERSAMAAN REGRESI } & \multicolumn{2}{|c|}{ FORECAST $(x=39)$} \\
\hline Jacket & $\mathrm{y}$ & 13,86555 & $0,0773 x$ & 16,88025 & $\rightarrow$ dibulatkan menjadi 17 unit \\
\hline Dress & $\mathrm{y}$ & 198,995 & $1,2289 \mathrm{x}$ & 246,9221 & $\rightarrow$ dibulatkan menjadi 247 unit \\
\hline Blouse & $\mathrm{y}$ & 222,8824 & $3,73 x$ & 77,4124 & $\rightarrow$ dibulatkan menjadi 78 unit \\
\hline Kebaya & $\mathrm{y}$ & 72,2521 & $0,7854 x$ & 41,6215 & $\rightarrow$ dibulatkan menjadi 42 unit \\
\hline Kaftan & $\mathrm{y}$ & 18,4958 & $0,1768 x$ & 11,6006 & $\rightarrow$ dibulatkan menjadi 12 unit \\
\hline Skirt & $\mathrm{y}$ & 9,739495 & $0,1319 x$ & 14,883595 & $\rightarrow$ dibulatkan menjadi 15 unit \\
\hline Pants & $\mathrm{y}$ & 32,92437 & $0,4244 x$ & 16,37277 & $\rightarrow$ dibulatkan menjadi 17 unit \\
\hline Shawl & $\mathrm{y}$ & 9,043697 & $0,1532 x$ & 3,068897 & $\rightarrow$ dibulatkan menjadi 4 unit \\
\hline
\end{tabular}

Sumber: Peneliti (2013)

Hasil pengolahan data menggunakan software QM for Windows 2 menunjukkan bahwa solusi dalam memberikan kombinasi produk yang tepat yang seharusnya diproduksi PT Astakarya Busanaprima pada periode Maret 2014 adalah 17 unit Jacket, 70,4074 unit Dress, 78 unit Blouse, 42 unit Kebaya, 12 unit Kaftan, 15 unit Skirt, 17 unit Pants, dan 4 unit Shawl dengan pendapatan maksimum sebesar Rp877.492.589,14. Tabel 10 menjelaskan secara lebih rinci.

Tabel 10 Tabel Pendapatan

\begin{tabular}{|c|c|c|c|}
\hline PRODUK & JUMLAH & HARGA & PENDAPATAN \\
\hline Jacket & 17 unit & $\operatorname{Rp} 4,000,000.00$ & Rp $68,000,000.00$ \\
\hline Dress & $\begin{array}{l}70,4074 \rightarrow 70 \text { unit dan } 0,4074 \\
\text { merupakan work-in-process }\end{array}$ & $\mathrm{Rp} 4,400,000.00$ & Rp $308,000,000.00$ \\
\hline Blouse & 78 unit & Rp 3,250,000.00 & Rp 253,500,000.00 \\
\hline Kebaya & 42 unit & Rp 3,300,000.00 & Rp $138,600,000.00$ \\
\hline Kaftan & 12 unit & Rp 3,600,000.00 & Rp $43,200,000.00$ \\
\hline Skirt & 15 unit & Rp $1,575,000.00$ & Rp $23,625,000.00$ \\
\hline Pants & 17 unit & Rp $1,575,000.00$ & Rp $\quad 26,775,000.00$ \\
\hline Shawl & 4 unit & Rp 3,500,000.00 & Rp $\quad 14,000,000.00$ \\
\hline \multicolumn{3}{|c|}{ TOTAL } & Rp 875,700,000.00 \\
\hline
\end{tabular}

Sumber: Peneliti (2013)

Terjadinya perbedaan perhitungan total pendapatan maksimum pada periode Maret 2014 disebabkan perbedaan dalam pembulatan angka. Jadi, nilai 70,4074 unit yang dianggap akan dijual adalah 70 unit. Sisanya 0,5926 masih dalam tahap pengerjaan (work-in-process) yang belum selesai pada periode Maret 2014, sehingga pada periode Maret 2014 sebaiknya PT Astakarya Busanaprima memproduksi 17 unit Jacket, 70 unit Dress, 78 unit Blouse, 42 unit Kebaya, 12 unit Kaftan, 15 unit 
Skirt, 17 unit Pants, dan 4 unit Shawl untuk dapat memaksimalkan pendapatan sebesar Rp875.700.000,00.

Dalam output Ranging, didapatkan bahwa masih terdapat slack atau surplus yang menggambarkan sisa dari penggunaan input (sumber daya) dalam proses produksi, yakni pada penggunaan waktu kerja, kain jenis 1 , kain jenis 2, benang, benang bordir, lapisan dalam, kain keras, manik-manik, dan retsleting serta pemenuhan permintaan Dress. Sedangkan input (sumber daya) yang telah digunakan dengan optimal adalah penggunaan kancing juga pemenuhan peramalan permintaan untuk Jacket, Blouse, Kebaya, Kaftan, Skirt, Pants, dan Shawl, yang memiliki nilai slack (surplus) sebesar 0. Dengan demikian, agar PT Astakarya Busanaprima dapat mencapai pendapatan yang optimal serta memproduksi dengan efektif dan efisien, diharapkan dapat melakukan pemberdayaan tenaga kerja sehingga dapat memaksimalkan waktu kerja, bahan baku dan bahan pendukung dapat lebih dimanfaatkan, sehingga dapat menjalankan kegiatan produksi yang lebih baik dengan tingkat produktivitas yang tinggi dan mengalokasikan input (sumber daya) yang masih ada untuk memproduksi Dress lebih banyak lagi, sehingga dapat menjawab setiap permintaan yang ada.

\section{SIMPULAN}

Pertama, metode peramalan yang paling optimal untuk meramalkan jumlah penjualan tiap produk bagi PT Astakarya Busanaprima adalah Linear Regression karena memiliki nilai Mean Absolute Deviation (MAD) yang terkecil dari semua metode yang digunakan dalam penelitian ini. Kedua, perkiraan jumlah penjualan yang dapat diperoleh PT Astakarya Busanaprima pada periode Maret 2014 untuk produk jacket, dress, blouse, kebaya, kaftan, skirt, pants, dan shawl secara berturutturut : 17 unit, 247 unit, 78 unit, 42 unit, 12 unit, 15 unit, 17 unit, dan 4 unit. Ketiga, kombinasi produk yang tepat dan efisien yang harus diproduksi bagi PT Astakarya Busanaprima pada periode Maret 2014 adalah 17 unit jacket, 70 unit dress, 78 unit blouse, 42 unit kebaya, 12 unit kaftan, 15 unit skirt, 17 unit pants, dan 4 unit shawl.

\section{DAFTAR PUSTAKA}

Astuti, N. E. D., Linawati, L., \& Mahatma, T. (2013). Penerapan model linear goal programming untuk optimasi perencanaan produksi. Prosiding Seminar Nasional Sains dan Pendidikan Sains Fakultas Sains dan Matematika UKSW, 8(4), 464-471.

Gass, S. I., \& Fu, M. C. (Eds.). (2013). Encyclopedia of Operations Research and Management Science (3 ed.). New York: Springer.

Heizer, J. \& Render, B. (2009). Manajemen Operasi. 9th Ed, Vol. 1. Jakarta: Salemba Empat.

Igwe, K. C. \& Onyenweaku, C. E. (2013). A linear programming approach to food crops and livestock enterprises planning in aba agricultural zone of Abia state, Nigeria. American Journal of Experimental Agriculture, 3(2), 412-431.

Render, B., Stair Jr., R. M., \& Hanna, M. E. (2012). Quantitative Analysis for Management. 11th Edition. England: Pearson Education.

Taylor III, B. W. (2005). Introduction to Management Science. 8th Edition. New Jersey: Prentice Hall.

Wignjosoebroto, S. (2003). Pengantar Teknik \& Manajemen Industri. Surabaya: Guna Widya. 